\title{
Laboratory Study on the Performance of Asphalt Mixes Modified with a Novel Composite of Diatomite Powder and Lignin Fiber
}

\author{
Moustafa Abdelsalam 1,2 ${ }^{\mathbb{D}}$, Yanchao Yue ${ }^{1, * \mathbb{D}}$, Ahmed Khater ${ }^{1,2}$, Dong Luo ${ }^{1}$, \\ Josephine Musanyufu ${ }^{1}$ and Xiaoli Qin ${ }^{3}$ \\ 1 School of Human Settlements and Civil Engineering, Xi'an Jiao tong University, Xi'an 710054, China; \\ moustafa91@stu.xjtu.edu.cn (M.A.); ahmedkhater@stu.xjtu.edu.cn (A.K.); luodong@xjtu.edu.cn (D.L.); \\ quinnnatukunda@gmail.com (J.M.) \\ 2 Department of Civil Engineering, Faculty of Engineering, Benha University, Benha 13512, Egypt \\ 3 School of Earth Science and Land Resources, Chang'an University, Xi'an 710064, China; \\ qinx12011@chd.edu.cn \\ * Correspondence: yuey@xjtu.edu.cn; Tel.: +86-1839-250-0205
}

Received: 12 July 2020; Accepted: 7 August 2020; Published: 10 August 2020

\begin{abstract}
The performance and the fundamental weaknesses of asphalt mix under environmental temperature and water effects have made researchers try to modify the asphalt mix properties by using the proper additives. For this reason, this paper aims to improve the anti-cracking performance and water stability of asphalt pavement by adding a novel composite of diatomite and lignin fiber in asphalt mixes. Four types of asphalt mixes, including control asphalt mix (CAM), diatomite modified asphalt mix (DMAM), lignin fiber modified asphalt mix (LFMAM), and diatomite-lignin fiber composite modified asphalt mix (DLFMAM) were prepared in the laboratory. Low-temperature bending test, Marshall Immersion test, and freeze-thaw splitting test were employed to evaluate the performance of the asphalt mixes. Results reveal that the use of the lignin fiber in reinforced asphalt mixes combined with diatomite led to an enhancement in the asphalt pavement performance more than the other three types of mixes. Diatomite has an important influence on the water damage resistance of asphalt mix more than lignin fiber. On the other hand, diatomite has a small effect on the anti-cracking performance; meanwhile, lignin fiber showed a significant improvement in the cracking resistance of asphalt mixes. DLFMAM has the best traveling performances among all asphalt mixes. Thus, this work provides a good reference for the design of composite asphalt mixes.
\end{abstract}

Keywords: lignin fiber; diatomite powder; asphalt mixes; low-temperature cracking resistance; water stability

\section{Introduction}

Asphalt pavement is a composite material consisting of aggregate, air void, asphalt mastic, and filler. It is considered the primary paving type of road and airport constructions, due to their good riding quality, low noise, fast construction speed, excellent durability and stability, recyclability, and easy maintenance [1-3]. In the last few decades, the Chinese government intended to improve the transportation industry by increasing the highway network in China over 130,000 km by the end of 2016, and more than $90 \%$ of that is asphalt pavement [4]; meanwhile, in the U.S., the asphalt pavements represent about $95 \%$ of total pavement structures [5].

However, under the effects of repeated vehicle loading and environmental conditions, asphalt pavements are susceptible to thermal cracking, especially at low temperatures in winter, and freeze-thaw 
cycles in the autumn, spring, and winter [6,7], which are deemed the main distresses that affect the asphalt pavements' properties in the cold regions.

Under low temperature, the thermal cracking in asphalt pavement appears in the form of transverse cracks on the top surface of the pavement structure and propagates downward over time [8-10], causing water to permeate into the asphalt pavement structure. The high porosity of the asphalt mix also plays an important role in the trapping of harmful water and air [11]. The moisture causes stripping, raveling, and fatigue damage through weakening the bonding force among asphalt mortar and aggregates $[12,13]$. Finally, these distresses can decrease the service period and decrease the quality of asphalt pavement with increased maintenance cost.

Therefore, researchers realized that the utilization of additives in asphalt mixes is the best method to apply to decrease consumption of natural resources, extend the service life, and improve asphalt pavement properties in case the pavement structure cannot withstand the climate effects and high traffic loads [14-16]. Among various types of additives, both lignin fiber and diatomite powder, were chosen to modify the behavior of asphalt mix under low temperature and water effects, based on the recommendation of the previous study [17].

Lignin fiber is an organic fiber produced from the chemical treatment of wood, with high heat resistance and stable chemical in acidic conditions. Furthermore, lignin fiber has a flocculent structure and rough surface. Flocculent structures can increase the absorption and stabilization of the asphalt binder, while the rough surface improves its adhesion with asphalt [7]. Lignin fiber has been used to improve the performance of asphalt mixes for many years [18-24].

Zhen Fu et al. [18] investigated the performance of asphalt mix modified with lignin fiber and anti-rutting agent. It is reported that the bending tensile strain of mixes obviously increased when using lignin fiber compared to anti-rutting agent, and lignin fiber substantially enhanced water-damage resistance. Zhen Fu et al. [19] also investigated the asphalt mix modified with lignin fibers and polymers. It concluded that both moisture sensitivity and low-temperature properties of modified asphalt mixes are better than the unmodified mix. Hasi Tuya [20] tested the low-temperature performance and water stability of asphalt mixes modified with lignin fiber and rubber. It showed that the anti-cracking and moisture-damage resistance of lignin fiber and rubber modified asphalt mix are clearly improved more than that modified with rubber only. Rui Xiong et al. [21] showed that the bending strength, the failure strain, as well as moisture susceptibility of asphalt mixes were significantly improved with the addition of lignin fiber. In comparison with other fibers, Qinwu Xu et al. [22] showed that lignin fiber had the highest anti-cracking property of asphalt mix, but it had the lowest performance in freeze-thaw cycle resistance. Gang Xu et al. [23] and Thanh et al. [24] evaluated the water stability performance of stone mastic asphalt mixes, which showed that Marshall residual stability was improved with the addition of lignin fiber.

Diatomite powder is an inorganic filler that has obtained a great interest due to its low density, low cost, low thermal conductivity, light weight $[25,26]$, and plentiful storage. The reserve of diatomite in China exceeds 300 million tons, ranking second after the United States [27]. Diatomite has been widely used to modify the asphalt pavement with the objective of reducing environmental pollution and producing asphalt mixes with high mechanical properties [28]. Various researchers studied the performance of asphalt mixes modified with diatomite [29-36].

Chao Yang et al. [29] showed that diatomite has little enhancement on the resistance of cracking of asphalt mixes, although the water stability values of diatomite modified asphalt mix were significantly increased compared to that of the unmodified mix. Hu Qiusheng [30] observed that the use of diatomite in pavement had a small influence on the asphalt mixes at low temperatures. Yongchun Cheng et al. [31] revealed that the use of diatomite in sand asphalt mixes improved the low-temperature performance with increased bending tensile strength. Arash Davar et al. [32] conducted a study on modifying asphalt mix by using a combination of diatomite and basalt fibers, which showed an improvement in the anti-cracking property of mixes. However, it also reported that the diatomite had small effects on the low-temperature behavior, since it improved the tensile strength but reduced the failure strain. Yiqiu Tan et al. [33] investigated the effect of diatomite on the anti-cracking property of asphalt mixes. 
Results displayed improvement in the low-temperature property of asphalt mixes. Another study was carried out by Guo et al. [34] on a compound of diatomite and glass fiber used to modify the asphalt mix. Their results demonstrated that the bad effect of diatomite on the low-temperature property of asphalt mix was overcome by using glass fiber. Nurul Athma et al. [35] and Shunjie Luo et al. [36] investigated the property of asphalt mix modified with diatomite under freeze-thaw cycle effects. It reported that the moisture damage resistance was clearly improved by using diatomite.

According to the aforementioned research and the previous review [17], it is clear that using diatomite or lignin fiber can improve the asphalt mixes but in different degrees. As the performance of asphalt mixes modified by diatomite or lignin fiber is similar in some effects and different in another, the utilization of double-adding technology into mixes may be more useful on the resistance of asphalt pavement to distress than the single adding. In addition, based on the literature, the optimal content of diatomite varies from $12 \%$ to $14 \%$, while the optimal dosage of lignin fiber is between $0.2 \%$ and $0.4 \%$. Thus, in the present study, diatomite was selected to be $13 \%$ of the weight of asphalt binder, and lignin fiber was chosen to be $0.3 \%$ of the weight of the asphalt mix.

The aim of this study to assess the performance of the asphalt mix modified with a novel composite of diatomite and lignin fiber, where the effects of the new composite on the properties of asphalt mix are still unknown. Therefore, if diatomite powder and lignin fiber are used to modify asphalt mix simultaneously, a new type of asphalt mix which has good low-temperature resistance and water stability performance may be obtained. Additionally, it will provide decision-makers with a reference for the design of composite asphalt mixes.

In this paper, three points bending, Marshall immersion, and freeze-thaw splitting tests were carried out on different types of asphalt mixes including control asphalt mix (CAM), diatomite modified asphalt mix (DMAM), lignin fiber modified asphalt mix (LFMAM), and diatomite-lignin fiber composite modified asphalt mix (DLFMAM). Based on the comparative experiment, the composite modified asphalt mix is evaluated compared to the other mixes.

\section{Materials and Methods}

\subsection{Materials}

\subsubsection{Aggregate and Mix Gradation}

Aggregates selected in the present study were limestone, obtained from an asphalt pavement plant in Xi'an city, Shaanxi Province of China. The properties of coarse aggregate and fine aggregate are listed in Tables 1 and 2, respectively, based on the requirement of Chinese specification [37]. Levitated limestone was used as the mineral filler, which has a hydrophilic coefficient of 0.773 and a relative density of 2.577. The selected gradation of the mixed aggregates is given in Figure 1.

Table 1. Properties of coarse aggregate.

\begin{tabular}{cccc}
\hline \multirow{2}{*}{ Property } & \multicolumn{2}{c}{ Measured Value } & \multirow{2}{*}{ Specified Value } \\
\cline { 2 - 3 } & $\mathbf{2 0 - 1 0 ~ \mathbf { ~ m m }}$ & $\mathbf{1 0 - 5 \mathbf { m m }}$ & \\
\hline Crushing value (\%) & 9.9 & 9.2 & $\leq 25$ \\
\hline Los Angeles abrasion value (\%) & 13.2 & 15.1 & $\leq 30$ \\
\hline Apparent relative density & 2.726 & 2.722 & $\geq 2.5$ \\
\hline Water absorption (\%) & 0.354 & 0.829 & $\leq 3$ \\
\hline$>9.5$ mm needle and plate particle content (\%) & 6.53 & & $\leq 15$ \\
\hline$<9.5$ mm needle and plate particle content (\%) & & 3.285 & $\leq 20$ \\
\hline
\end{tabular}


Table 2. Properties of fine aggregate.

\begin{tabular}{ccc}
\hline Property & Measured Value & Specified Value \\
\hline Apparent relative density & 2.692 & $\geq 2.5$ \\
\hline Sand equivalent & 82 & $\geq 60$ \\
\hline Mud content $(<0.075$ content $)(\%)$ & 16.78 & \\
\hline
\end{tabular}

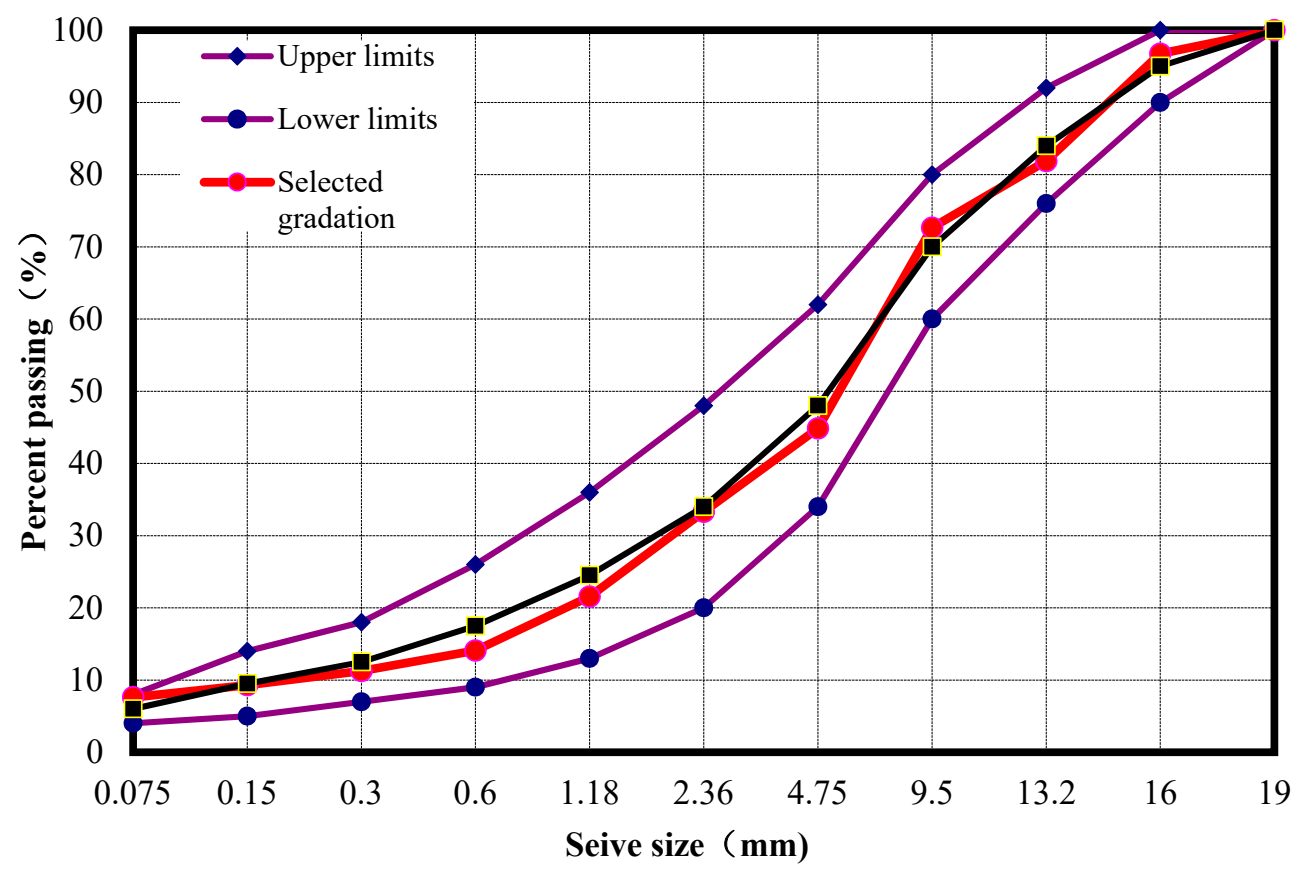

Figure 1. Asphalt concrete (AC-16) gradation design selected in the experiments.

\subsubsection{Asphalt Binder}

Asphalt binder AH-90 was chosen as heavy load asphalt in all experiments in this study. The physical indexes of asphalt binder, as per Chinese specifications [38], are presented in Table 3.

Table 3. Measured values of asphalt binder.

\begin{tabular}{cccc}
\hline Material & Item & Values & Specification \\
\hline \multirow{3}{*}{ Original asphalt binder } & Specific gravity $\left(\mathrm{g} / \mathrm{cm}^{3}\right)$ & 1.017 & N/A \\
\cline { 2 - 4 } & Penetration at $25^{\circ} \mathrm{C}(0.1 \mathrm{~mm})$ & 93 & $(80-100)$ \\
\cline { 2 - 4 } & Penetration Index PI & -1.27 & $-1.5 \sim+1.0$ \\
\cline { 2 - 4 } & Ductility at $15{ }^{\circ} \mathrm{C}(\mathrm{cm})$ & 145 & $\geq 100$ \\
\cline { 2 - 4 } & Softening point $\left({ }^{\circ} \mathrm{C}\right)$ & 45.9 & $\leq \pm 0.8$ \\
\hline \multirow{2}{*}{ RTOF asphalt binder } & Mass loss $(\%)$ & 0.07 & $\geq 20$ \\
\cline { 2 - 4 } & Ductility at $15{ }^{\circ} \mathrm{C}(\mathrm{cm})$ & 73.7 & $\geq 60$ \\
\cline { 2 - 4 } & Residual Penetration ratio $(\%)$ & 72.8 & \\
\hline
\end{tabular}

\subsubsection{Lignin Fiber}

Lignin fiber is a short fiber supplied from Beijing Tiancheng Kentelai Tec. Co., Ltd., China, and its fundamental properties provided by the manufacturer are listed in Table 4. The morphology of the lignin fiber is shown in Figure 2a. 
Table 4. Basic Properties of lignin fiber.

\begin{tabular}{ccccccc}
\hline Index & $\begin{array}{c}\text { Length } \\
(\mathbf{m m})\end{array}$ & $\begin{array}{c}\text { Diameter } \\
(\mathbf{m m})\end{array}$ & $\begin{array}{c}\text { Aspect Ratio } \\
(\mathbf{m e a n})\end{array}$ & $\begin{array}{c}\text { Specific Surface Area } \\
\left(\mathbf{1 0}^{-3} \mathbf{~ m}^{\mathbf{2}} \mathbf{g}\right)\end{array}$ & $\begin{array}{c}\text { Density } \\
\left(\mathbf{g} / \mathbf{c m}^{\mathbf{3}}\right)\end{array}$ & $\begin{array}{c}\text { Melt } \\
\text { Temperature }\left({ }^{\circ} \mathbf{C}\right)\end{array}$ \\
\hline Value & 1.1 & 0.045 & 24 & 118.1 & 1.28 & $>200$ \\
\hline
\end{tabular}

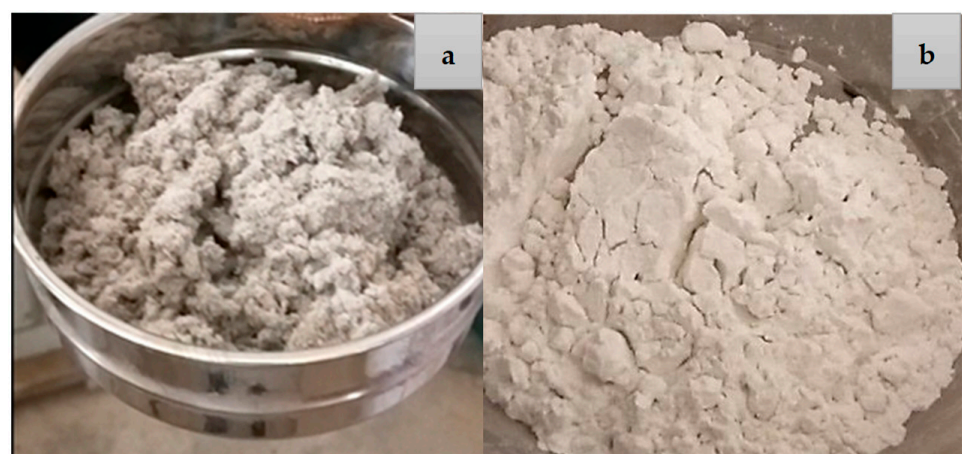

Figure 2. (a) View of lignin fiber; (b) diatomite.

\subsubsection{Diatomite}

Diatomite powder produced by Zhou Yifeng Chemical Technology Co., Ltd, in Guangdong Province, China, was selected in the current research to modify the asphalt mixes. A photo of diatomite powder is shown in Figure $2 b$, and its basic properties provided by the manufacturer were presented in Table 5. The particle size distribution of the diatomite is shown in Figure 3.

Table 5. Fundamental characteristics of diatomite.

\begin{tabular}{cc}
\hline Property & Measured Value \\
\hline Bulk density $\left(\mathrm{g} / \mathrm{cm}^{3}\right)$ & 0.45 \\
\hline Specific gravity $\left(\mathrm{g} / \mathrm{cm}^{3}\right)$ & 2.3 \\
\hline The average particle diameter $(\mu \mathrm{m})$ & 20 \\
\hline $\mathrm{pH}$ & 9.87 \\
\hline
\end{tabular}

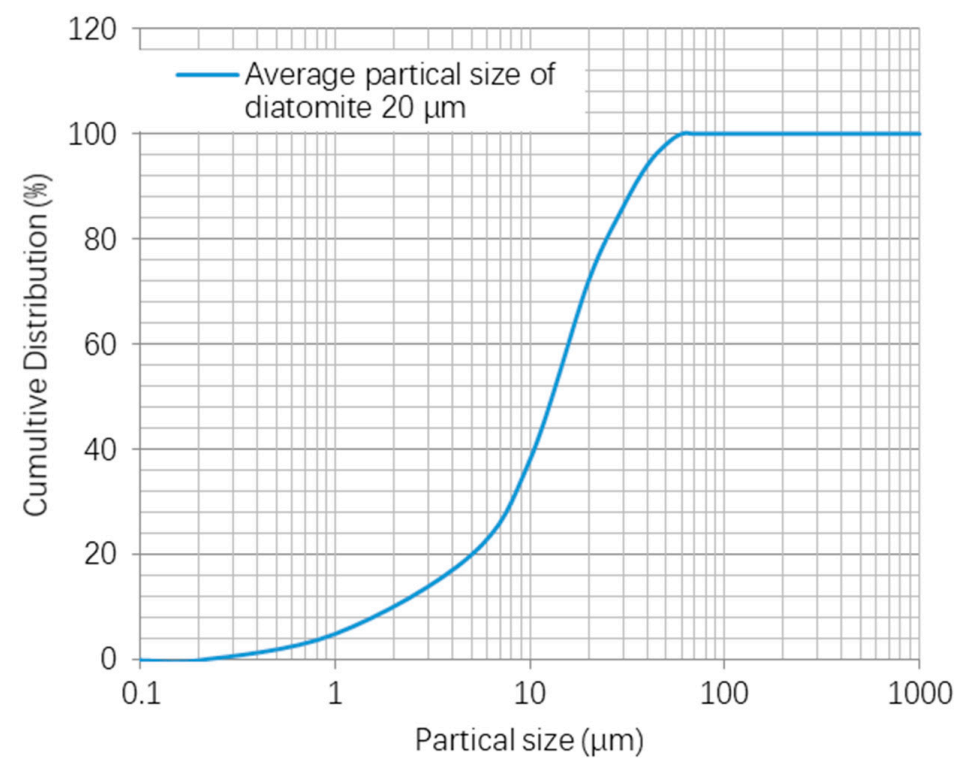

Figure 3. Particle size distribution of the diatomite. 


\subsection{Experimental Design}

Four different asphalt mixes, i.e., CAM, LFMAF, DMAM, and DLFMAM, were prepared with the optimum asphalt content. From the Marshall Design method [37], four identical specimens (101.6 diameter by $63.5 \mathrm{~mm}$ high) were manufactured in the laboratory for each type of asphalt mix. The specimens were compacted with 75 blows on each side using a Marshall Compactor. After that, the optimum asphalt content can be calculated based on Marshall Test results. The modifiers amount and optimum asphalt content (O.A.C) results are summarized in Table 6.

Table 6. Marshall Test values of asphalt mixes.

\begin{tabular}{cccc}
\hline Mix ID & Modifier & Modifier Amount & O.A.C. $\%$ \\
\hline CAM & NON & 0 & 4.2 \\
\hline LFMAM & Lignin fiber & $0.3 \% *$ & 4.6 \\
\hline DMAM & Diatomite & $13 \% * *$ & 4.27 \\
\hline DLFMAM & Lignin fiber + Diatomite & $0.3 \%^{*}+13 \%{ }^{* *}$ & 4.52 \\
\hline
\end{tabular}

${ }^{*}$ Lignin fiber percent of asphalt mix weight ${ }^{* *}$ Diatomite amount percent of asphalt binder weight.

The lignin fiber modified asphalt mixes show the largest optimum asphalt content, followed by DLFMAM and DMAM. The lignin fiber plays a key role in the increasing of the optimum asphalt content in LFMAM and DLFMAM due to its large surface area that helps absorb more asphalt [39].

\subsection{Preparation of the Samples}

There are two methods for adding the modifiers in the asphalt mix: the direct method and the indirect method. For the direct method, the modifier is added directly in the mixing process of the asphalt mix, while for the indirect method, the modifier is first blended with asphalt binder by using a high-speed shear mixer, and then the modified asphalt mixes are prepared with modified asphalt binder. Previous studies showed that the two methods have the same mix effect [40-42]. Consequently, the direct method was applied to the current research, and the preparation processes of DLFMAM are detailed as follows:

- Aggregates and asphalt were heated to temperatures of $170^{\circ} \mathrm{C}$ and $160^{\circ} \mathrm{C}$, respectively, till the material temperature was stable.

- The preheated aggregates were mixed at a temperature of $175^{\circ} \mathrm{C}$ in the mixing pot for $90 \mathrm{~s}$.

- Lignin fiber was added to aggregates, and then they were mixed together about $90 \mathrm{~s}$ in order to improve the dispersion of fibers in the asphalt mix.

- Asphalt binder (Bitumen) was poured into the mixer and mixed for $90 \mathrm{~s}$.

- Finally, diatomite and mineral filler were added and mixed $90 \mathrm{~s}$ to form DLFMAM.

Excluding the modified materials addition, the preparation processes of CAM, LFMAM, and DMAM were the same as DLFMAM. Time and temperature of mixing at each step were similar to those of DLFMAM.

\subsection{Test Methods}

\subsubsection{Three-Points Bending Test (Beam Bending Test)}

When exposed to low temperatures, asphalt pavement may suffer from thermal cracking [43]. Therefore, three-point beam bending test was employed to evaluate the low-temperature performance of asphalt mixes by determining the ultimate tensile strength and ultimate strain [8].

The laboratory compacted square slab with dimensions of $300 \times 300 \times 50 \mathrm{~mm}$ was cut to three identical beam specimens measuring $250 \mathrm{~mm}$ in length by $30 \mathrm{~mm}$ in width by $35 \mathrm{~mm}$ in height, following 
Chinese standard requirements [38]. The specimens were submerged inside a water container at a fixed temperature of $-10^{\circ} \mathrm{C}$ for $1 \mathrm{~h}$ before testing. Afterward, a three-point bending test was carried out with a loading rate of $50 \mathrm{~mm} / \mathrm{min}$ on the beam specimen with a span length of $200 \mathrm{~mm}$ at $-10^{\circ} \mathrm{C}$ using the Material Testing System (MTS-810). The specimens and bending machine are shown in Figure 4. During the test, the max load and middle displacement on the top surface of the beam sample were recorded. The bending strength and the bending strain can be calculated as follows [44],

$$
\begin{aligned}
R_{B} & =\frac{3 L P_{B}}{2 b h^{2}} \\
\varepsilon_{B} & =\frac{6 h d}{L^{2}}
\end{aligned}
$$

where $\mathrm{RB}$ is bending strength $(\mathrm{MPa}), \varepsilon_{\mathrm{B}}$ is bending strain $(\mu \varepsilon)$, $\mathrm{L}$ is span length $(\mathrm{mm}), \mathrm{PB}$ is the maximum loading at failure $(\mathrm{N}), \mathrm{b}$ is beam width $(\mathrm{mm}), \mathrm{h}$ is beam height $(\mathrm{mm})$, and $\mathrm{d}$ is the mid-span-deflection at failure $(\mathrm{mm})$.

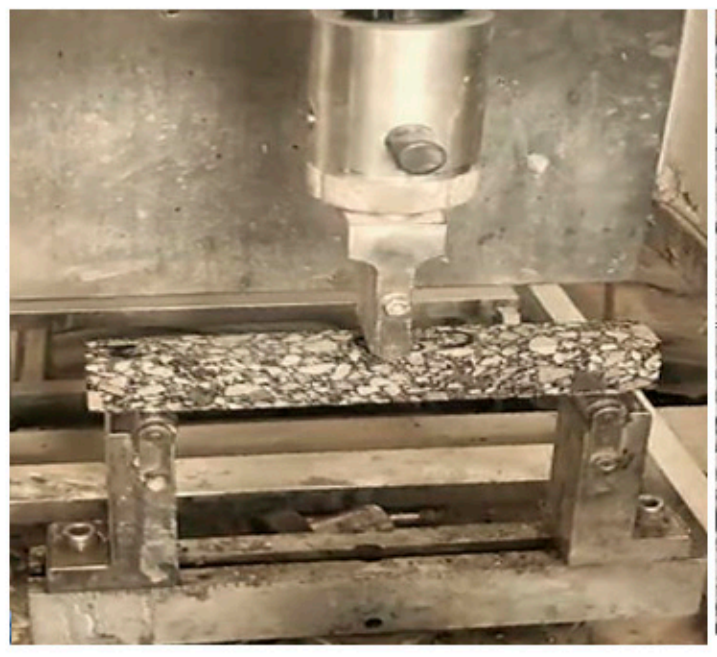

(a)

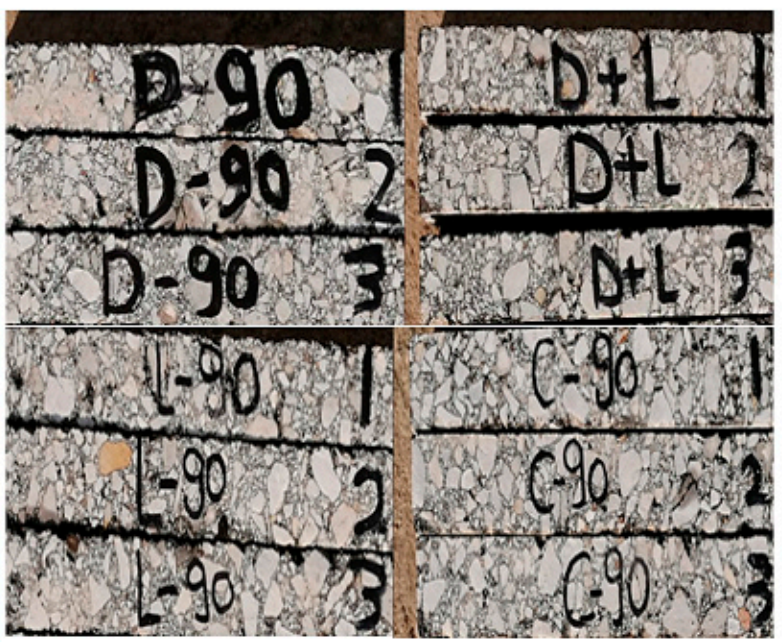

(b)

Figure 4. (a) Bending test machine; (b) samples of three-point bending test.

\subsubsection{Marshall Immersion Test}

The Marshall Immersion test is considered one of the widely used methods to evaluate the resistance of asphalt mixes to the moisture susceptibility by calculating the Residual Marshall Stability ratio (RMS).

Six duplicated cylindrical samples were prepared with a diameter of $101.6 \mathrm{~mm}$ and a height of $63.5 \mathrm{~mm}$. The samples were divided into two equivalent groups, and each group had three samples. One group was immersed in a water bath for $30 \mathrm{~min}$ at a temperature of $60^{\circ} \mathrm{C}$, while the other group was immersed in a water bath at a constant temperature of $60^{\circ} \mathrm{C}$ for $48 \mathrm{~h}$. The Marshall Stability test was performed on each group, and the Residual Marshall Stability ratio (RMS) was determined by the following equation [44],

$$
\mathrm{RMS} \%=\frac{\mathrm{MS}_{2}}{\mathrm{MS}_{1}} \times 100
$$

where RMS is the residual Marshall Stability, $\mathrm{MS}_{2}$ is Marshall Stability after $48 \mathrm{~h}$ water effect at $60{ }^{\circ} \mathrm{C}$, and $\mathrm{MS}_{1}$ is Marshall Stability after $30 \mathrm{~min}$ water effect at $60^{\circ} \mathrm{C}$. 


\subsubsection{Freeze-Thaw Splitting Test}

The freeze-thaw splitting test is the other method used to assess the water stability performance of asphalt mixes under the effect of freeze-thaw cycles by calculating the indirect tensile strength ratio (TSR), which is defined as the tensile strength ratio between the frozen-thawed samples and fresh samples [45].

Two groups of identical cylindrical samples (101.6 $\mathrm{mm}$ in diameter and $63.5 \mathrm{~mm}$ in height) were fabricated, and the group consisted of three samples. The samples in the first group were vacuumed in water under a pressure of $98.3-98.7 \mathrm{kPa}$ for $15 \mathrm{~min}$, then cured in a water bath for $20 \mathrm{~min}$ at $25^{\circ} \mathrm{C}$. After curing, each sample was sealed in a plastic bag filled with $10 \mathrm{~mL}$ of water and placed in a freezer for $16 \mathrm{~h}$ at $-18{ }^{\circ} \mathrm{C}$. The frozen samples were thawed at a temperature of $60^{\circ} \mathrm{C}$ for $24 \mathrm{~h}$. After that, the frozen-thawed specimens and the second group (three fresh specimens) were submerged in a water bath at a temperature of $25{ }^{\circ} \mathrm{C}$ for $2 \mathrm{~h}$. Finally, indirect tensile tests were conducted on both the frozen-thawed and fresh samples with a loading rate of $50 \mathrm{~mm} / \mathrm{min}$ at $25^{\circ} \mathrm{C}$, as per the specification [44], and the indirect tensile strength ratio (TSR) was calculated as follows [38],

$$
\begin{gathered}
\mathrm{R}_{\mathrm{t}}=\frac{0.006287 \mathrm{P}_{\mathrm{t}}}{\mathrm{h}} \\
\mathrm{TSR} \%=\frac{\mathrm{R}_{\mathrm{t} 2}}{\mathrm{R}_{\mathrm{t} 1}} \times 100
\end{gathered}
$$

where TSR is the indirect tensile strength ratio, $R_{t 2}$ is the average indirect tensile strength of the frozen-thawed samples (MPa), $R_{t 1}$ is the average indirect tensile strength of the fresh samples (MPa), $P_{t}$ is the tensile failure load $(N)$, and $h$ is the height of the sample $(\mathrm{mm})$.

\section{Results Analysis and Discussion}

The results of low-temperature bending, Marshall Immersion, and freeze-thaw splitting tests for the performance of the four different types of asphalt mixes under low temperature and water cycle effects are presented in Table 7. The result of each test is explained and analyzed in detail as presented in this section separately.

\begin{tabular}{|c|c|c|c|c|c|c|c|c|}
\hline \multirow[b]{2}{*}{ Asphalt Mix ID } & \multicolumn{2}{|c|}{ Low-Temperature Cracking Test } & \multicolumn{3}{|c|}{ Marshall Immersion Test } & \multicolumn{3}{|c|}{ Freeze-Thaw Splitting Test } \\
\hline & $\begin{array}{l}\text { Stress } \\
\text { (Mpa) }\end{array}$ & $\begin{array}{l}\text { Strain } \\
\left(10^{-6}\right)\end{array}$ & $\begin{array}{l}\mathrm{MS}_{1} \\
\text { (KN) }\end{array}$ & $\begin{array}{l}\mathrm{MS}_{2} \\
\text { (KN) }\end{array}$ & $\begin{array}{c}\text { MSR } \\
(\%)\end{array}$ & $\begin{array}{c}\mathrm{R}_{\mathrm{T} 1} \\
\text { (Mpa) }\end{array}$ & $\begin{array}{c}\mathrm{R}_{\mathrm{T} 2} \\
\text { (Mpa) }\end{array}$ & $\begin{array}{l}\text { TSR } \\
(\%)\end{array}$ \\
\hline CAM & 7.51 & 2018.4 & 10.95 & 9.09 & 83.0 & 0.711 & 0.553 & 77.77 \\
\hline LFMAM & 9.02 & 2589.12 & 11.02 & 9.93 & 90.11 & 0.738 & 0.593 & 80.35 \\
\hline DMAM & 8.11 & 2294 & 11.71 & 10.79 & 92.14 & 0.748 & 0.627 & 83.82 \\
\hline LFDMAM & 9.33 & 2762 & 12.11 & 11.51 & 95.05 & 0.773 & 0.659 & 85.25 \\
\hline
\end{tabular}

Table 7. Experimental results of different asphalt mixes.

\subsection{Low-Temperature Bending Test Results and Analysis}

A three-point bending test was conducted at $-10^{\circ} \mathrm{C}$ to evaluate the anti-cracking performance of asphalt mixes. The bending strength and failure strain of four kinds of asphalt mix are shown in Figures 5 and 6, respectively. The addition of lignin fiber significantly improved the bending strength and tensile strain of asphalt mixes by about $19.9 \%$ and $28.7 \%$, respectively, in comparison to the control mix. Meanwhile, the bending strength and tensile strain of asphalt mix modified with diatomite were slightly increased by $7.9 \%$ and $13.6 \%$, respectively, compared to that of the control mix. The composite asphalt mixes of diatomite and lignin fiber (DLFMAM) recorded the highest enhancement in the bending strength and tensile strain by $24.23 \%$ and $36.8 \%$, respectively, with respect to the values of control mix. 


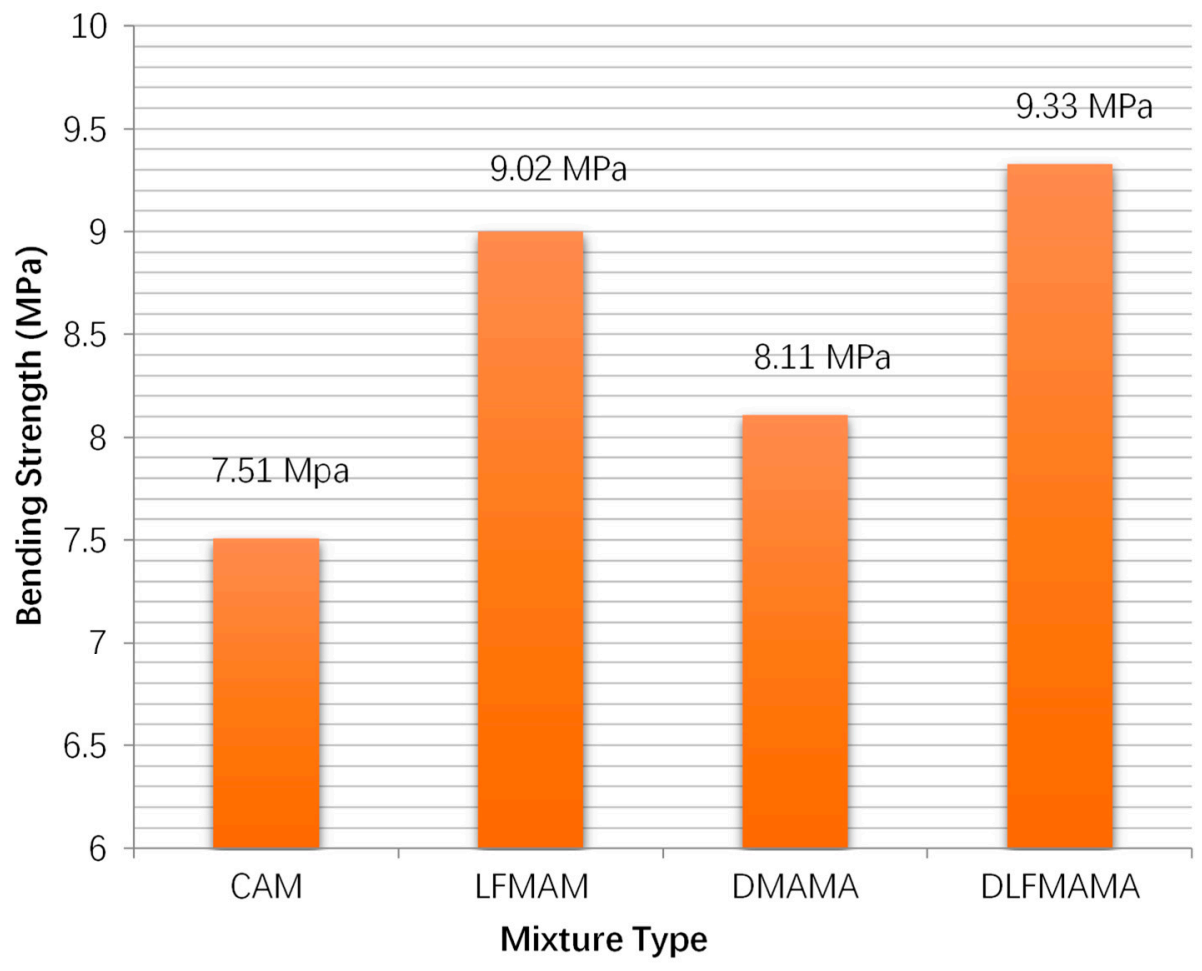

Figure 5. Bending strength of asphalt mixes.

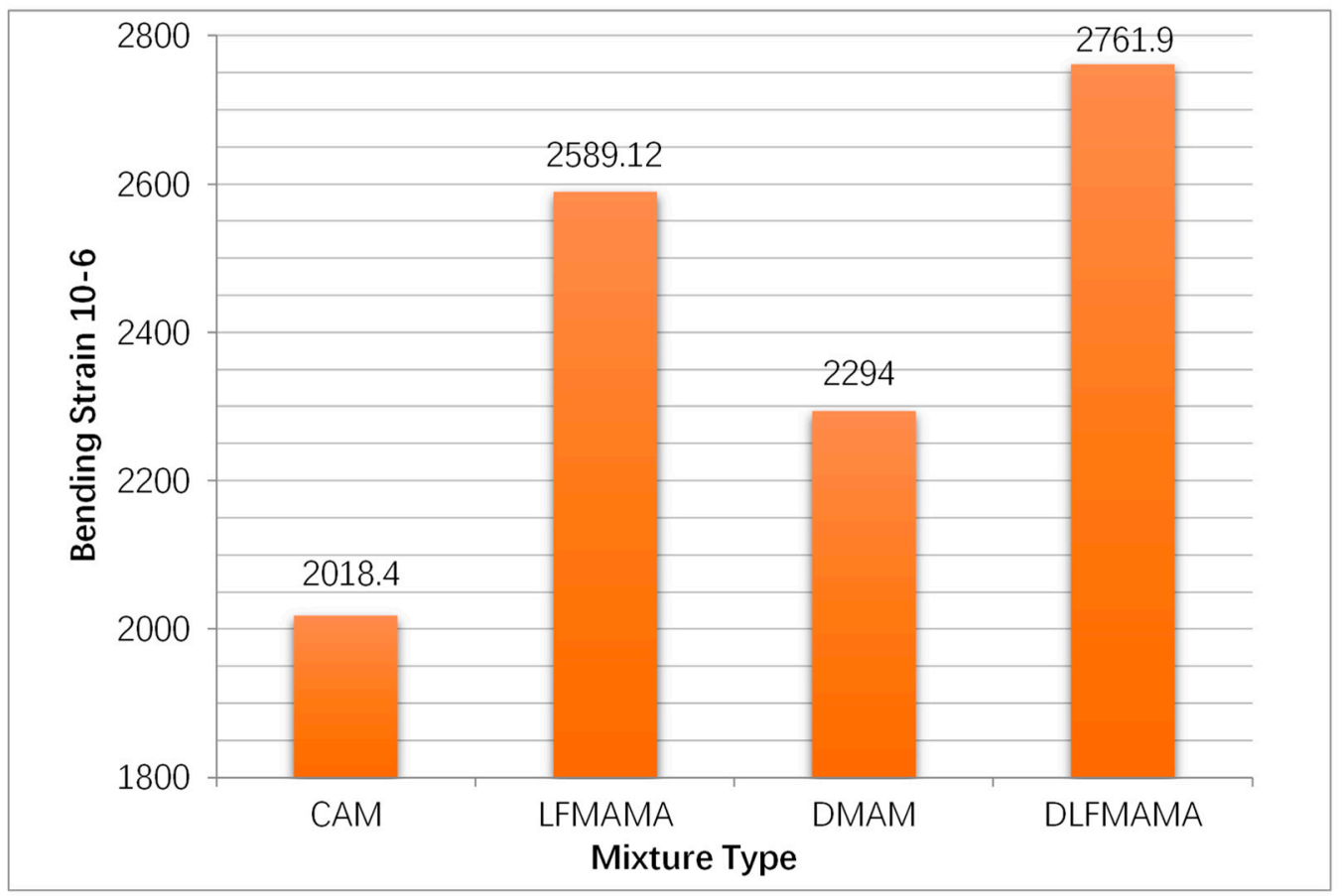

Figure 6. Ultimate bending strain of asphalt mixes.

The above results can be addressed with a certain mechanism. The asphalt binder filled among aggregates plays a major role in bonding when the temperature drops, so the asphalt mix does not crack easily. However, when the temperature is dropped to a certain extent, the base asphalt binder becomes unable to resist the extreme tensile stress, and cracks appear. If these cracks expanded it would be risky on the pavement service life and pavement strength. Lignin fiber can improve the cracking resistance of asphalt mixes, where it has a high specific surface area through which more amounts of asphalt 
components can be easily absorbed. The greater the absorption of asphalt binder, the greater the viscosity of asphalt, which enhances the interface adhesion strengths. Furthermore, the asphalt content absorbed by lignin fiber increases the flexibility of asphalt mixes since more asphalt films are formed to better perform the filling and healing functions in the micro-cracks among aggregates. Additionally, as shown in Figure 7, the three-dimensional lignin fiber is uniformly distributed in the asphalt mix. Therefore, after it is added to the asphalt mix, the bridging phenomenon happens among the asphalt mix components. The lignin fibers which go through both sides of the crack surface grow a bridge shape which can delay more asphalt cracking. Therefore, the toughness of lignin fiber can improve the anti-cracking performance, redistribute the stress in asphalt mix, and decrease crack spread rates in the asphalt pavement structure.

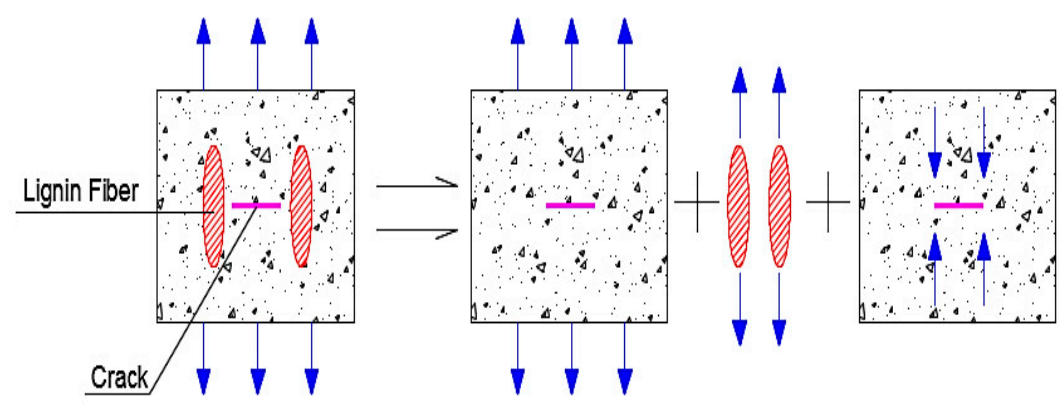

Figure 7. Crack and lignin fiber.

On the other hand, diatomite has a small influence on the enhancement of low-temperature performance. That is to say, diatomite tends to improve the hardness of asphalt, which may improve the mechanical properties and the cracking resistance of mix to a certain extent. After that, the low-temperature cracking may appear. Nevertheless, diatomite powder, unlike the fibers, has no cross-linking with asphalt to act as bridges to hold asphalts and transfer stress once cracking appears.

For these reasons, under the combined action of lignin fiber and diatomite, the anti-cracking performance of the composite asphalt mix is significantly improved compared to that of the other three types of mixes.

\subsection{Water Stability Test Results}

\subsubsection{Marshall Immersion Test Results}

Results of immersion Marshall Stability values (MS1, MS2), and Residual Marshall Stability ratio (RMS) are summarized in Table 7 and Figure 8. Results indicated that the modified asphalt mixes containing not only lignin fiber but also diatomite powder had a higher resistance to moisture damage. The asphalt mixes modified with lignin fiber and diatomite improved the RMS to $7.11 \%$ and $9.14 \%$, respectively, as compared to the control mix. Furthermore, the composite asphalt mixes of diatomite and lignin fiber (DLFMAM) achieved the greatest moisture susceptibility performance among the four types of asphalt mixes, with an increase of nearly $12.05 \%$ in RMS than that of control mix. 


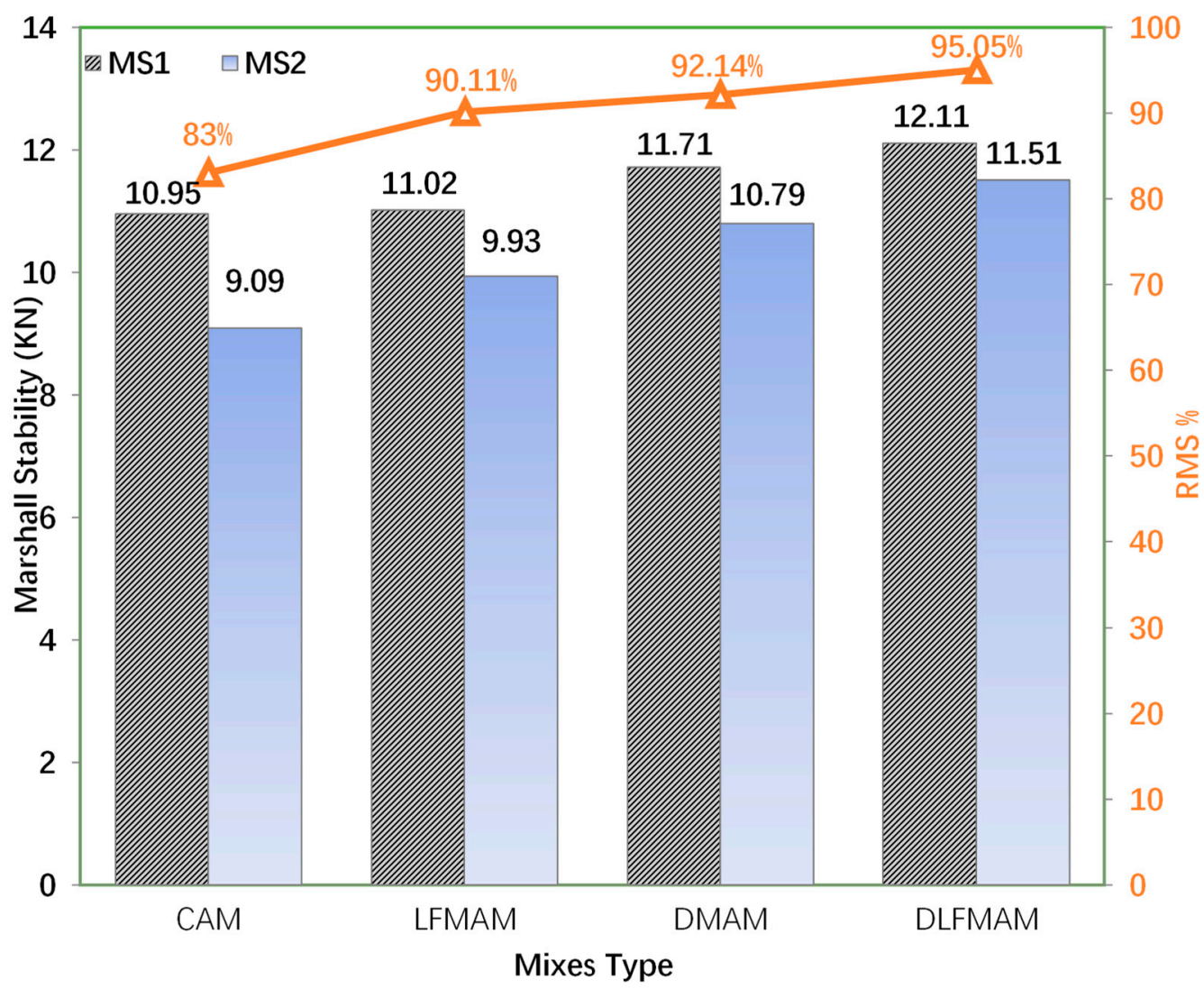

Figure 8. Results of the Immersion Marshall Stability test.

\subsubsection{Freeze-Thaw Splitting Test Results}

The results of the indirect tensile strength from the normal temperature group (RT1), freezing and thawing group (RT2), and tensile strength ratio (TSR) are presented in Table 7 and Figure 9. Results showed that the water stability performance of asphalt mixes modified with lignin fiber and diatomite were increased by $2.6 \%$ and $6.05 \%$, respectively, compared to the control mix. Meanwhile, the TSR of the composite asphalt mix modified with of diatomite and lignin fiber (DLFMAM) was better than the other three types of mixes, where the TSR of DLFMAM was improved about $7.5 \%$ as opposed to the values of control mix.

In summary, the results of water stability tests indicated that the addition of lignin fiber and diatomite improved the water damage resistance of asphalt mixes. Nonetheless, the asphalt mix modified with diatomite is superior to that modified with lignin fiber. In addition, the composite asphalt mix of diatomite and lignin fiber (DLFMAM) is greater than the asphalt mix which is only modified with lignin fiber or diatomite.

These results can be analyzed as moisture susceptibility is related to the combination of asphalt film and aggregate, as well as the additives type. After adding diatomite and lignin fiber, the parameter values of the modified asphalt mix was higher than that of unmodified asphalt mix, leading to the increase of the cohesive force between the asphalt mastic and the aggregate. Finally, it will lead to an improvement in the shear resistance and stability of mixes. In addition, the RMS and TSR of asphalt mixes modified with lignin fiber are lower than that modified with diatomite. This is likely due to the air voids; the asphalt mixes modified with lignin fiber will be harder to compact, and the void of mixes would also increase.

In addition, Figures 8 and 9 show that the Residual Marshall Stability ratio (RMS) is higher than the tensile strength ratio (TSR). The reason is that the specimens for the Marshall Immersion test were compacted about 75 times for each side, which leads to reduce the porosity of mixes to $3-5 \%$. As a result, it became difficult to penetrate water through the voids between aggregate and asphalt film. 
On the contrary, freeze-thaw splitting test specimens were only compacted 50 times, so the porosity of mixes increased to $7 \%$.

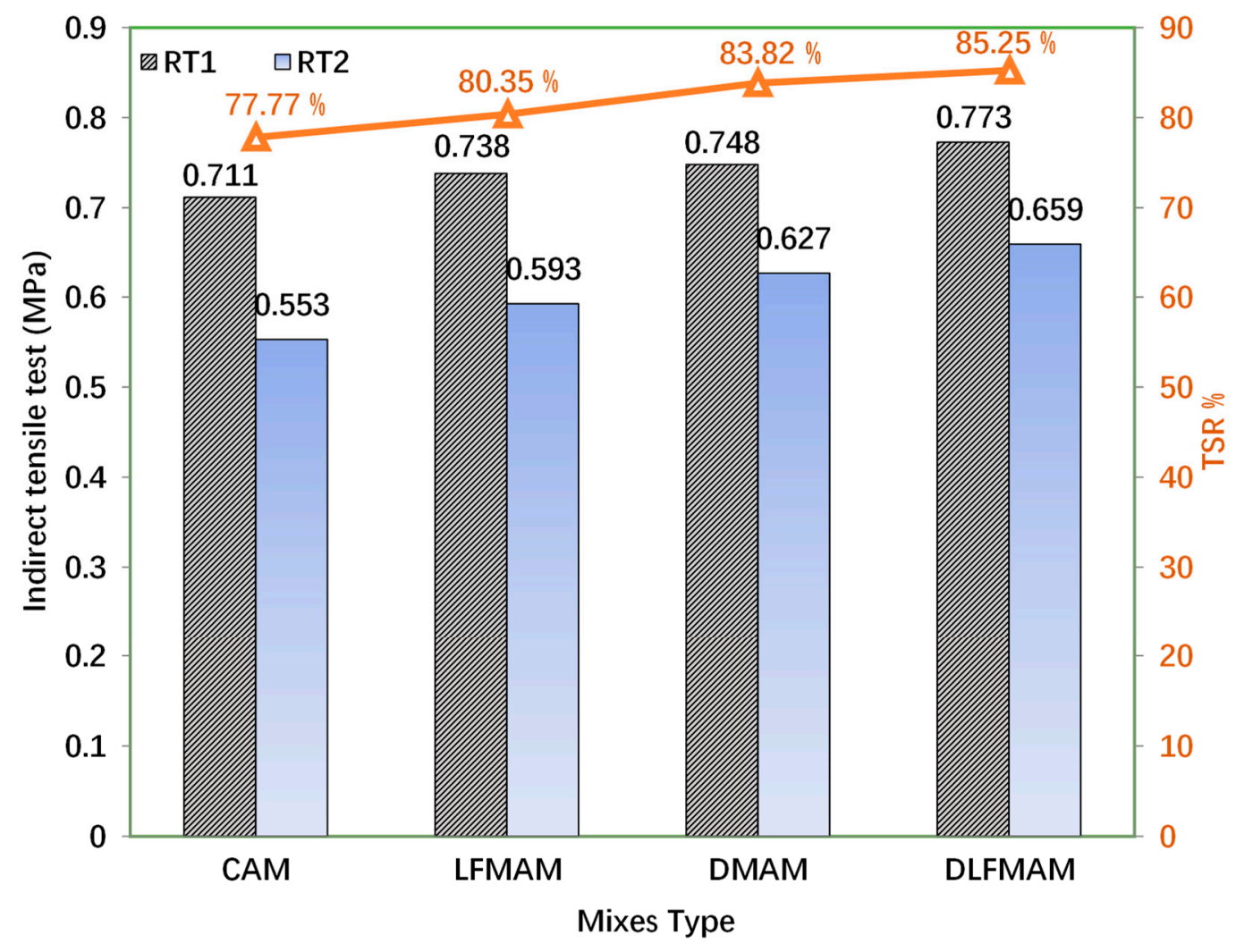

Figure 9. Results of the indirect tensile test.

\section{Conclusions}

In this paper, four types of asphalt mixes (CAM, DMAM, LFMAM, and DLFMAM) have been evaluated under low temperatures and water effect. From the experimental results of three points bending, Marshall immersion and freeze-thaw splitting tests, the following main conclusions can be outlined:

- The addition of diatomite and lignin fiber increase the low-temperature performance of asphalt mixes compared to the control mix. Moreover, the lignin fiber has a greater improvement in the bending strength and failure strain than the diatomite.

- Diatomite and lignin fiber improve water damage resistance of asphalt mixture significantly. However, the influence of diatomite on water damage resistance property is more significant than that of lignin fiber.

- The composite asphalt mix of diatomite and lignin fiber (DLFMAM) is the best alternative to resist low-temperature cracking and moisture sustainability in asphalt pavements since it has the highest low-temperature performance, MSR, and TSR than other mixes.

- The Asphalt mixes modified with single additives cannot enhance the overall properties of asphalt mixes significantly, while the double-adding technology can improve the overall asphalt mixes performance at the same time.

- Using the composite asphalt mix of DLFMAM in construction of pavement will have a greater advantage in enhancing the service life and ride quality than the usage of single additives in pavements constructed. 
In summary, the pavement constructed with composite asphalt mix of DLFMAM will have a better traveling performance than that constructed with a single additive of diatomite or lignin fiber. A trial section of DLFMAM should be constructed in the future to determine its applicability in cold regions.

Author Contributions: Conceptualization and design of experiment, M.A., and A.K.; experiment, validation, and formal analysis, M.A. and A.K. Project administration, Y.Y.; writing-original draft preparation, M.A. and A.K.; writing-review and editing, M.A., A.K., and J.M.; supervision, Y.Y., D.L., and X.Q. All authors have read and agreed to the published version of the manuscript.

Funding: This research was funded by Central University's special research funding special fund cross-disciplinary project (xj2017174). This research was also funded by Natural Science Foundation Research Program of Shaanxi Province-Youth Talents Project (51408481).

Acknowledgments: A financial support from CSC (Chinese Scholarship Council) is gratefully acknowledged.

Conflicts of Interest: The authors declare no conflict of interest.

\section{References}

1. Chen, Z.; Wu, S.; Pang, L.; Xie, J. Function investigation of stone mastic asphalt (SMA) mixture partly containing basic oxygen furnace (BOF) slag. J. Appl. Biomater. Funct. Mater. 2016, 14 (Suppl. S1), 68-72. [CrossRef] [PubMed]

2. Sadeghnejad, M.; Arabani, M.; Taghipoor, M. Predicting the impact of temperature and stress on the glasphalt mixtures' rutting behavior. Int. J. Pavement Res. Technol. 2018, 11, 300-310. [CrossRef]

3. Luo, D.; Khater, A.; Yue, Y.; Abdelsalam, M.; Zhang, Z.; Li, Y.; Li, J.; Iseley, D.T. The performance of asphalt mixtures modified with lignin fiber and glass fiber: A review. Constr. Build. Mater. 2019, 209, 377-387. [CrossRef]

4. Long, Y.; Wu, S.; Xiao, Y.; Cui, P.; Zhou, H. VOCs reduction and inhibition mechanisms of using active carbon filler in bituminous materials. J. Clean. Prod. 2018, 181, 784-793. [CrossRef]

5. Mohod, M.V.; Kadam, K. A comparative study on rigid and flexible pavement: A review. IOSR J. Mech. Civ. Eng. 2016, 13, 84-88.

6. Liu, Z.; Xing, M.; Chen, S.; He, R.; Cong, P. Influence of the chloride-based anti-freeze filler on the properties of asphalt mixtures. Constr. Build. Mater. 2014, 51, 133-140. [CrossRef]

7. Chen, H.; Xu, Q. Experimental study of fibers in stabilizing and reinforcing asphalt binder. Fuel 2010, 89, 1616-1622. [CrossRef]

8. Pei-Wen, H.; Deng-Liang, Z.; Xi-Ning, H. Evaluation method for low temperature anti-cracking performance of asphalt mixture. J. Xi'an Highw. Unversity 2000, 20, 1-5.

9. Kanerva, H.K.; Vinson, T.S.; Zeng, H. Low-Temperature Cracking: Field Validation of the Thermal Stress Restrained Specimen Test; Strategic Highway Research Program SHRP-A: NW Washington, DC, USA, 1994.

10. Marker, V. Introduction to Non-Traffic Load Associated Cracking of Asphalt Pavements. In Proceedings of the Association of Asphalt Paving Technologists, Lino Lakes, MN, USA, 27 April 2012; pp. 239-247.

11. Mashaan, N.S.; Ali, A.H.; Koting, S.; Karim, M.R. Performance evaluation of crumb rubber modified stone mastic asphalt pavement in Malaysia. Adv. Mater. Sci. Eng. 2013, 2013, 1-8. [CrossRef]

12. Haghshenas, H.; Khodaii, A.; Saleh, M. Long term effectiveness of anti-stripping agents. Constr. Build. Mater. 2015, 76, 307-312. [CrossRef]

13. Kim, Y.-R.; Lutif, J.S.; Bhasin, A.; Little, D.N. Evaluation of moisture damage mechanisms and effects of hydrated lime in asphalt mixtures through measurements of mixture component properties and performance testing. J. Mater. Civ. Eng. 2008, 20, 659-667. [CrossRef]

14. Kim, Y.R. Modeling of Asphalt Concrete; ASCE Press: Reston, VA, USA, 2008.

15. Sienkiewicz, M.; Kucinska-Lipka, J.; Janik, H.; Balas, A. Progress in used tyres management in the European Union: A review. Waste Manag. 2012, 32, 1742-1751. [CrossRef] [PubMed]

16. Fitzgerald, R. Novel Application of Carbon Fiber for Hot Mix Asphalt Reinformortar and Carbon-Carbon Pre-Forms. Master's Thesis, Michigan Technological University, Houghton, MI, USA, 2000.

17. Yue, Y.; Abdelsalam, M.; Luo, D.; Khater, A.; Musanyufu, J.; Chen, T. Evaluation of the Properties of Asphalt Mixes Modified with Diatomite and Lignin Fiber: A Review. Materials 2019, 12, 400. [CrossRef] [PubMed]

18. Fu, Z.; Dang, Y.; Guo, B.; Huang, Y. Laboratory investigation on the properties of asphalt mixtures modified with double-adding admixtures and sensitivity analysis. J. Traffic Transp. Eng. 2016, 3, 412-426. [CrossRef] 
19. Fu, Z.; Shen, W.; Huang, Y.; Hang, G.; Li, X. Laboratory evaluation of pavement performance using modified asphalt mixture with a new composite reinforcing material. Int. J. Pavement Res. Technol. 2017, 10, 507-516. [CrossRef]

20. Tuya, H. The road performance of lignin and rubber powder composite modified asphalt mixture. Highw. Eng. 2014, 39, 170-174.

21. Xiong, R.; Fang, J.; Xu, A.; Guan, B.; Liu, Z. Laboratory investigation on the brucite fiber reinforced asphalt binder and asphalt concrete. Constr. Build. Mater. 2015, 83, 44-52. [CrossRef]

22. Xu, Q.; Chen, H.; Prozzi, J.A. Performance of fiber reinforced asphalt concrete under environmental temperature and water effects. Constr. Build. Mater. 2010, 24, 2003-2010. [CrossRef]

23. Xu, G.; Zhao, L.H.; Zhao, J. Research on Performance of Basalt Fiber-Enhanced SMA. In Advanced Materials Research; Trans Tech Publications Ltd.: Stafa-Zurich, Switzerland, 2011; pp. 4323-4327.

24. Thanh, D.V.; Feng, C.P.; Long, L.H. Analysis of high temperature stability and water stability of SMA mixture using orthogonal experiments. Int. J. Civil. Struct. Eng. 2011, 2, 635-647.

25. Jiang, L.; Liu, Q.L. Application of Diatomite Modified Asphalt. In Applied Mechanics and Materials; Trans Tech Publications Ltd.: Stafa-Zurich, Switzerland, 2014; pp. 959-963.

26. Cheng, Y.; Zhu, C.; Tan, G.; Lv, Z.; Yang, J.; Ma, J. Laboratory Study on Properties of Diatomite and Basalt Fiber Compound Modified Asphalt Mastic. Adv. Mater. Sci. Eng. 2017, 2017, 1-10. [CrossRef]

27. Liu, H.; Fu, L.; Jiao, Y.; Tao, J.; Wang, X. Short-term aging effect on properties of sustainable pavement asphalts modified by waste rubber and diatomite. Sustainability 2017, 9, 996.

28. Wei, H.; He, Q.; Jiao, Y.; Chen, J.; Hu, M. Evaluation of anti-icing performance for crumb rubber and diatomite compound modified asphalt mixture. Constr. Build. Mater. 2016, 107, 109-116. [CrossRef]

29. Yang, C.; Xie, J.; Zhou, X.; Liu, Q.; Pang, L. Performance Evaluation and Improving Mechanisms of Diatomite-Modified Asphalt Mixture. Materials 2018, 11, 686. [CrossRef] [PubMed]

30. Qiusheng, H.; Gang, Z. The Research on Improvement of Low Temperature Stability for Diatomite Modified Asphalt Mixture with PE Particles. Int. J. Eng. Res. Appl. 2015, 5, 1-5.

31. Cheng, Y.; Zhu, C.; Tao, J.; Jiao, Y.; Yu, D.; Xiao, B. Effects of Diatomite-Limestone Powder Ratio on Mechanical and Anti-Deformation Properties of Sustainable Sand Asphalt Composite. Sustainability 2018, 10, 808. [CrossRef]

32. Davar, A.; Tanzadeh, J.; Fadaee, O. Experimental evaluation of the basalt fibers and diatomite powder compound on enhanced fatigue life and tensile strength of hot mix asphalt at low temperatures. Constr. Build. Mater. 2017, 153, 238-246. [CrossRef]

33. Tan, Y.; Zhang, L.; Xu, H. Evaluation of low-temperature performance of asphalt paving mixtures. Cold Reg. Sci. Technol. 2012, 70, 107-112. [CrossRef]

34. Guo, Q.; Li, L.; Cheng, Y.; Jiao, Y.; Xu, C. Laboratory evaluation on performance of diatomite and glass fiber compound modified asphalt mixture. Mater. Des. 2015, 66, 51-59. [CrossRef]

35. Shukry, N.A.M.; Hassan, N.A.; Abdullah, M.E.; Hainin, M.R.; Yusoff, N.I.M.; Jaya, R.P.; Mohamed, A. Effect of various filler types on the properties of porous asphalt mixture. IOP Conf. Ser. Mater. Sci. Eng. 2018, 342, 012036. [CrossRef]

36. Luo, S.; Chen, N.; Xu, H.; Tan, B.; Chen, Q. Study on Indoor Pavement Performance of Diatomite-Modified Asphalt Mixture. In Proceedings of the 2016 International Conference on Innovative Material Science and Technology (IMST 2016), Shenzhen, China, 19-21 August 2016.

37. JTGF 40-2004. Technical Code for Construction of Highway Asphalt Pavement; Ministry of Communication of China: Beijing, China, 2004.

38. JTJ 052-2000. Specification for Highway Engineering Asphalt and Asphalt Concrete Mixture Experiments; C.M.o.T.: Beijing, China, 2000.

39. Wang, X.; Qiu, Y.-J.; Xue, S.-Y.; Yang, Y.; Zheng, Y. Study on durability of high-modulus asphalt mixture based on TLA and fibre composite modification technology. Int. J. Pavement Eng. 2018, 19, 930-936. [CrossRef]

40. Cheng, Y.; Yu, D.; Gong, Y.; Zhu, C.; Tao, J.; Wang, W. Laboratory evaluation on performance of eco-friendly basalt fiber and diatomite compound modified asphalt mixture. Materials 2018, 11, 2400. [CrossRef] [PubMed]

41. Abtahi, S.; Hejazi, S.; Sheikhzadeh, M.; Semnani, D. An investigation on the use of textile materials to mechanical reinforcement of asphalt-concrete (AC) structures and analysis of results by an artificial neural network (ANN). In Proceedings of the 4th National Congress on Civil Engineering, Tehran, Iran, 6 May 2008. NCCE04-127. 
42. Yin, H.Y. Research on the Modification Mechanism of Diatomite and Dry Mixing of Diatomite-Modified Asphalt Miture. Master's Thesis, Chongqing Jiaotong University, Chongqing, China, 2012.

43. Xu, Q.; Solaimanian, M. Measurement and evaluation of asphalt concrete thermal expansion and contraction. J. Test. Eval. 2008, 36, 140-149.

44. JTG E20-2011. Standard Test Methods of Asphalt and Asphalt Mixtures for Highway Engineering; Ministry of Transport: Beijing, China, 2011.

45. Pang, L.; Liu, K.; Wu, S.; Lei, M.; Chen, Z. Effect of LDHs on the aging resistance of crumb rubber modified asphalt. Constr. Build. Mater. 2014, 67, 239-243. [CrossRef] 